ج קكيده

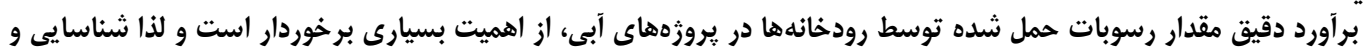

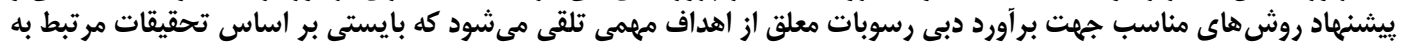

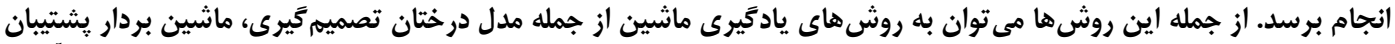

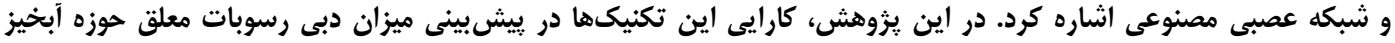

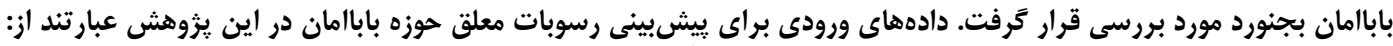

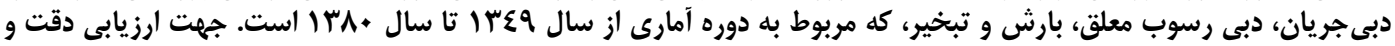

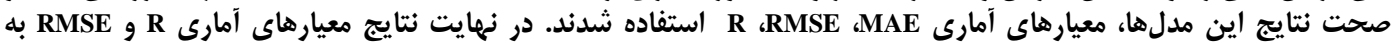

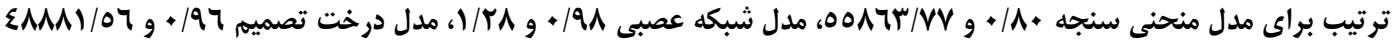

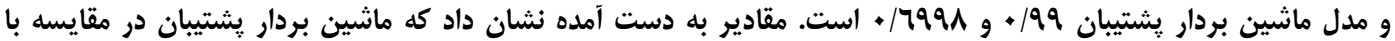

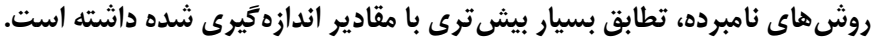

وازههاى كليدى: بار رسوب معلق، درخت تصميه، شبكه عصبى مصنوعى، ماشين بردار يشتيبان، منحنى سنجه رسوب

رسوب و شبكه عصبى در استان كلستان به اين نتيجه رسيدند

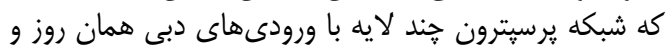

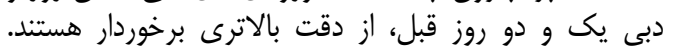

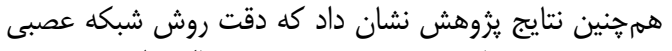

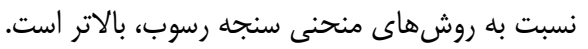

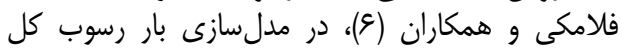

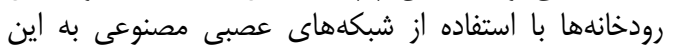

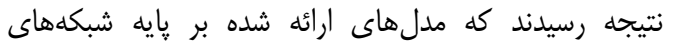

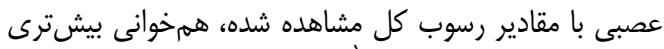

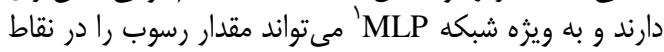

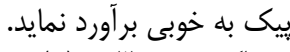

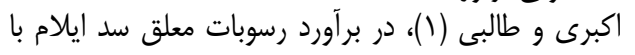

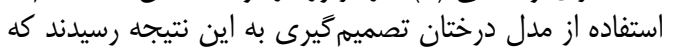

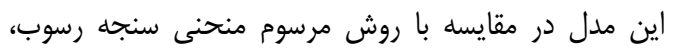

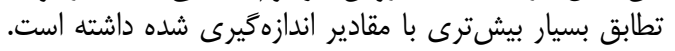

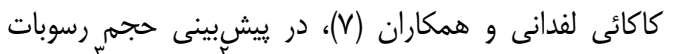

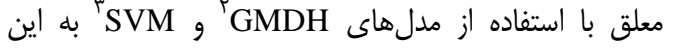

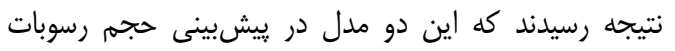

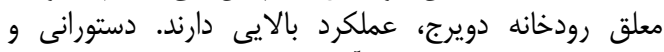

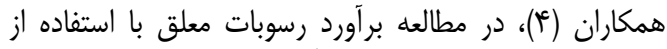

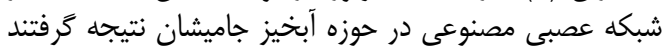

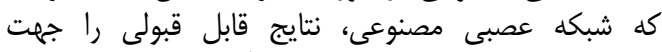

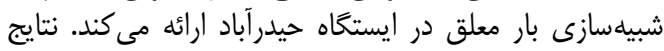

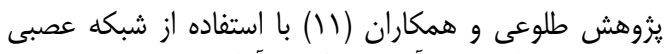

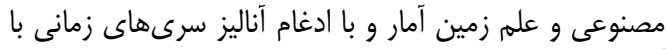

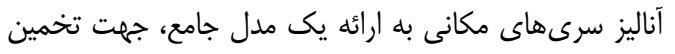

فرسايش و رسوبكذارى، فرآيندى است كه به از دست رفتن خاكهاى حاصل خيز حوزههاى آبخـيز و همجنين إنين ايجاد

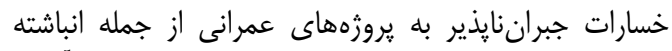

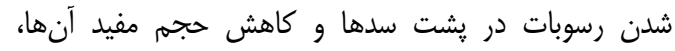

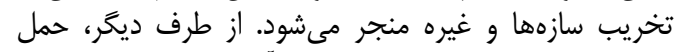

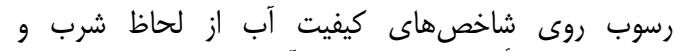

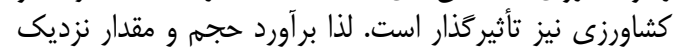

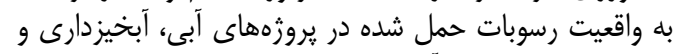

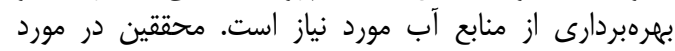

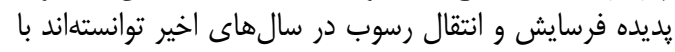

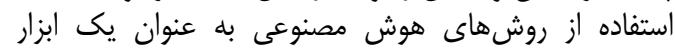
جديد، مقدار رسوبات معلق را محاسبه كنند.

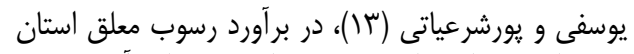

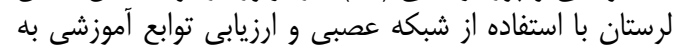

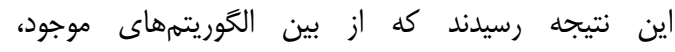

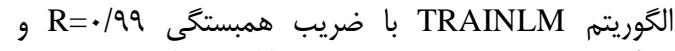
مMSE (ton/day) =•/1 .

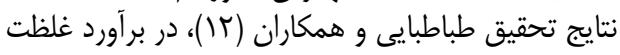

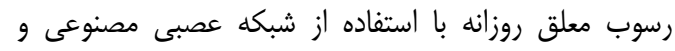

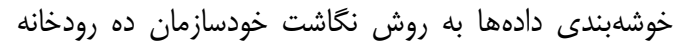

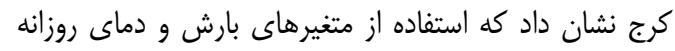

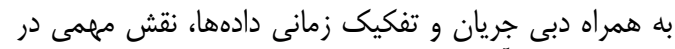
افزايش دقت برآورد رسوب رودخان توكانه داشته است.

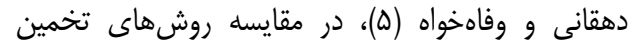

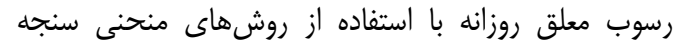


بنابراين با توجه به اهميت ميزان توليد رسوب معلق و و

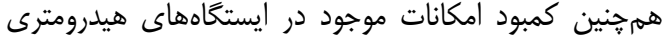

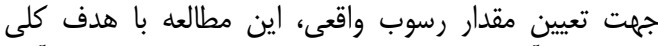

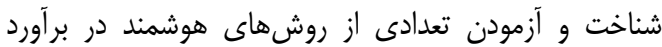
ميزان رسوب بار معلق و مقايسه نتايج آنها با مقاد مقادير مشاهدان

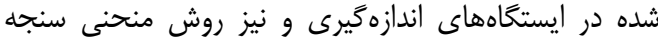
رسوب به اجرا در آمده است.

رودخانه باباامان در فاصله ماليه كيلومترى شمال شرقى رودي

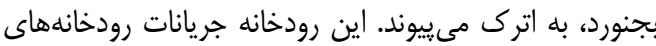

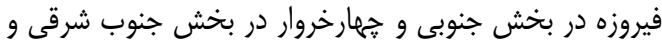

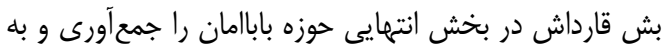

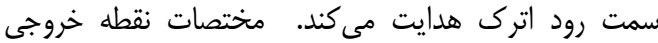

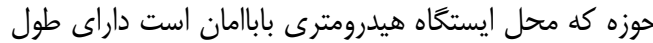
جغرافيايى (UTM)

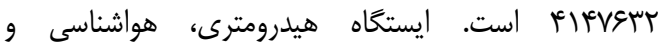

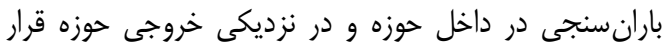

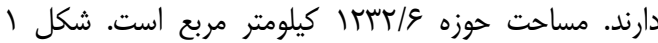

موقعيت جغرافيايى محدوده مورد مطالعه را نشان مى مدهد.
بار معلق ماهانه در طول رودخانه آجى جاى، نشاندهنده

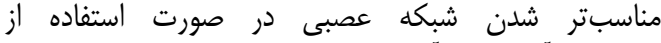

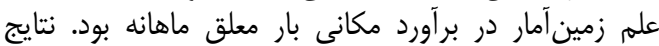

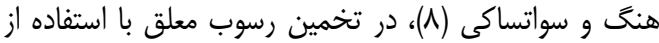

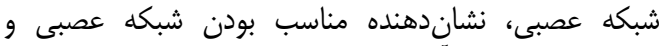
توانايى افزايش كارآيى مدل با استفاده از اطلاعات كليدى

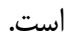

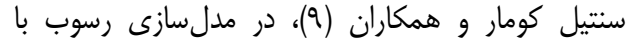

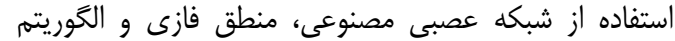

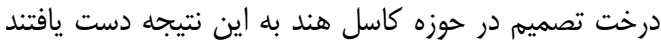

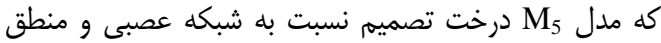

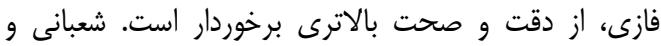

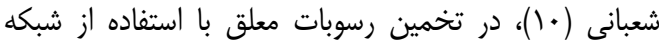

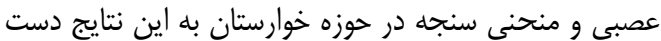

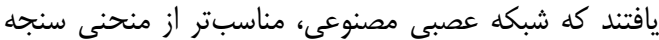

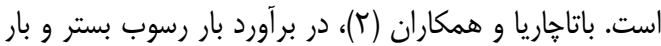

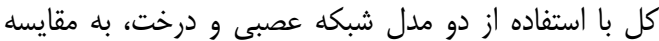

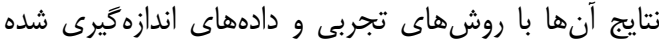

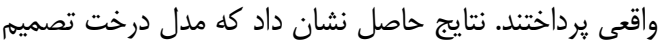

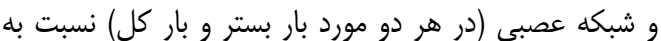
روشهاى تجربى، تطابق بهترى با دادههاى واقعى دارند،

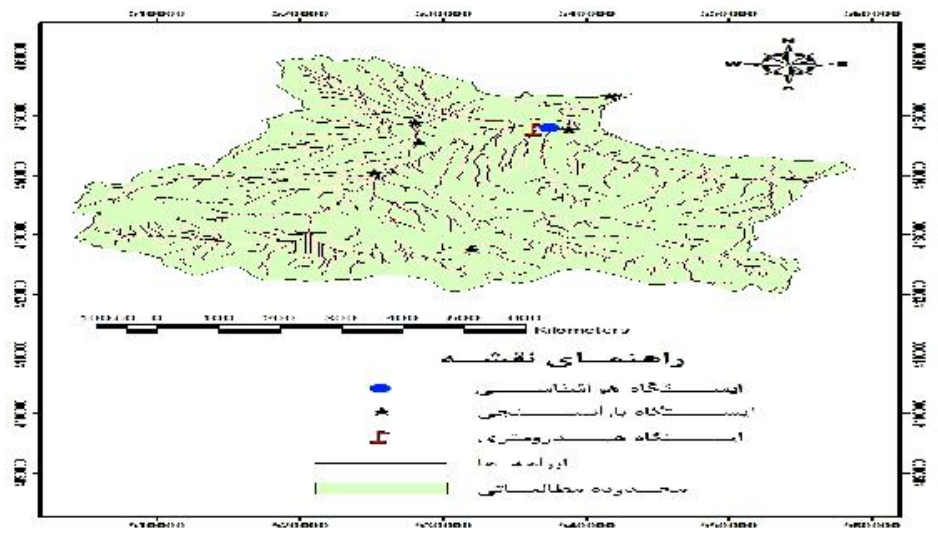

شكل ا- موقعيت جغر افيايى محدوده مورد مطالعه

Figure 1. The geographical location of the study area

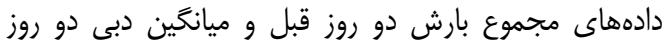

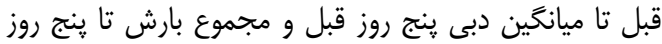

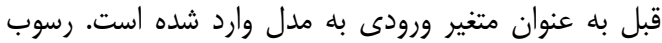
معلق هم به عنوان متغير خروجى مدل مدل است.

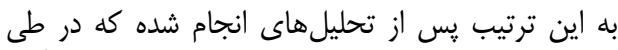

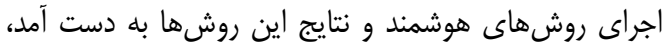

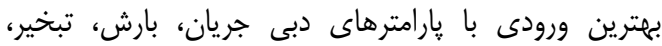

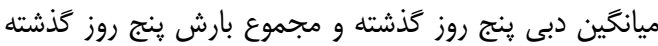

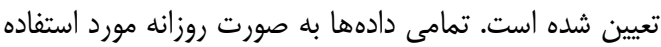

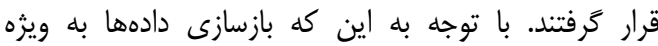

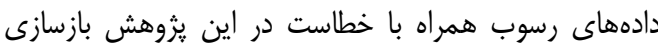
صورت نحَرفته است و فقط از دادههاى اندازمكيرى موجود در اين يزوهش جهت بروآورد رسوبات معلق از آمار ايستخاه

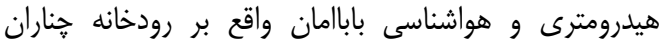

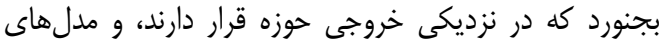

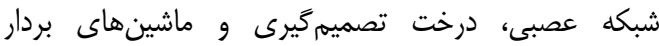

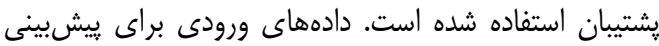

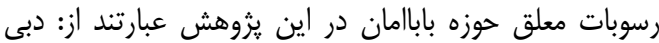

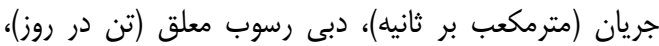

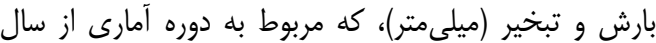

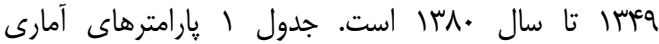

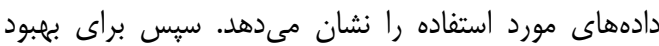
نتايج مدلها، با ثابت بودن دبى متناظر در هر بار اجراى مدلى مدل، 
است كه آمار بارامترهاى ديخر آن از جمله دبى جريان، بارش دوان

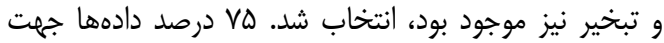

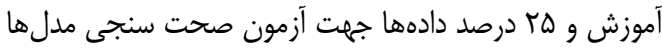

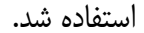

استفاده شده است. همخينين دادههاى استفاده شده در اين

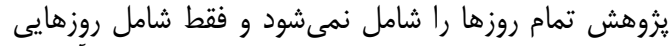

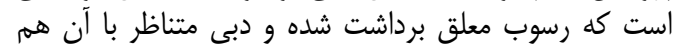

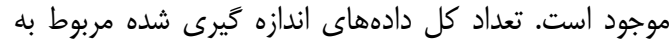

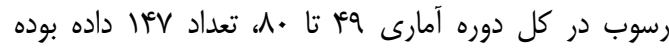
جدول ا- مقادير يارامترهاى آمارى دادهاى مورد استفاده Table 1. Values of statistical parameteres of the used data

\begin{tabular}{|c|c|c|c|c|}
\hline تبخير & بارش & دبى & خصوصيات أمارى & \multirow{4}{*}{ مرحله آموزش } \\
\hline $1 / \wedge \Delta$ & $\cdot \mid \Delta \Lambda$ & $1 / 4 V$ & ميانكين & \\
\hline - & - &.$/ D F$ & حداقل & \\
\hline $9 / 4$. & ז' & V/at & حداكثر & \\
\hline $1 / T V$ & $r / \cdot V$ & $\cdot / A F$ & ضريب تغييرات & \\
\hline r & $T / \& \Delta$ & r/Q & ميانكَين & \multirow{4}{*}{ مرحله آزمون } \\
\hline - & - & $\cdot / 199$ & حداقل & \\
\hline$\Lambda / V$ & IV & $9 / 1 T$ & حداكثر & \\
\hline ./va & $1 / 99$ &.$|9|$ & ضريب تغييرات & \\
\hline
\end{tabular}

در مدل منحنى سنجه رسوب، يك رابطه رگرسيونى بين

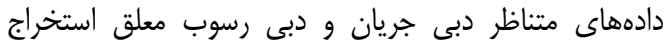

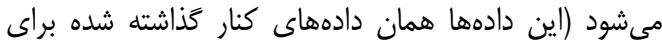

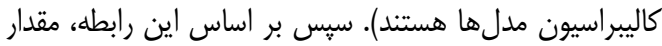

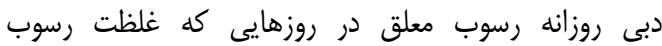

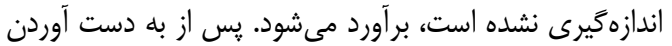

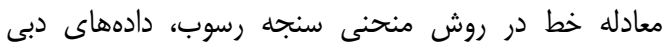

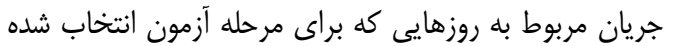

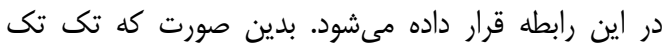

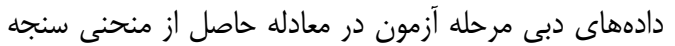

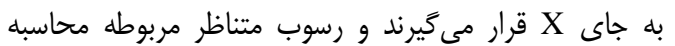

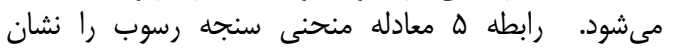

$$
Q_{s}=a Q_{w}^{b}
$$

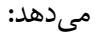

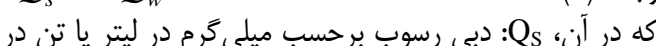

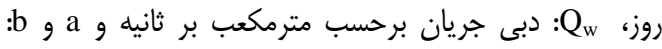
ضرايب ثابت معادله هستند.

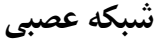

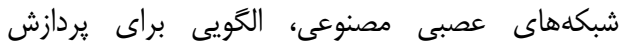

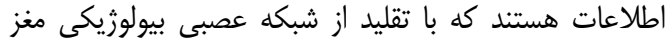

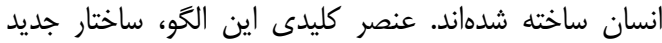

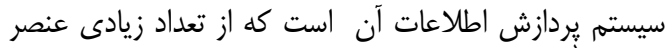

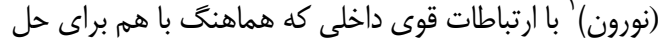

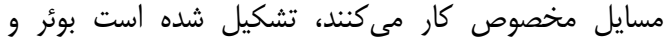

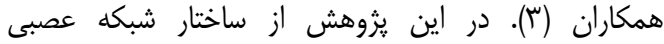

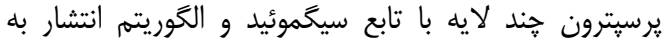
عقب استفاده شده است.

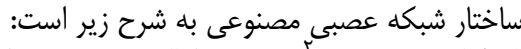

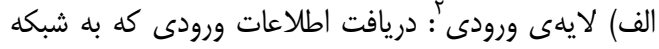

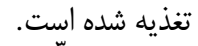

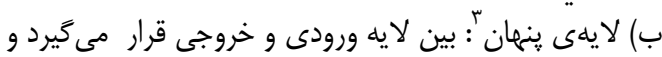
محاسبات در اين لايه صورت بين لايه وروى ميردو
براى اجرا و محاسبات روشهاى نامبرده از نرمافزار مطلب

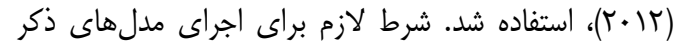

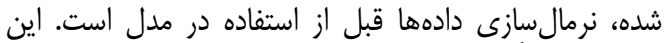

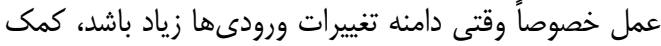

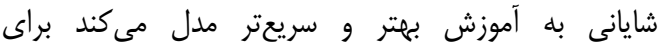

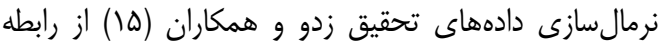

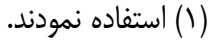

$X_{n}=\left(\frac{X-X_{\min }}{X-X_{\max }}\right)$

كه اين رابطه، X: معرف داده مشاهده شده، و و

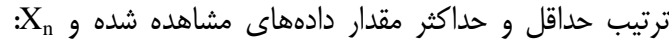

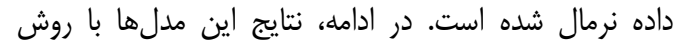

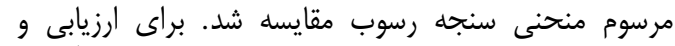

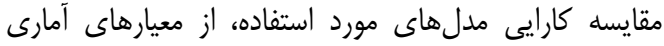

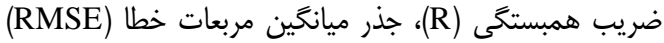
و خطاى مطلق (MAE) طبق روابط زير استفاده شده است:

$R=\frac{\sum\left(O_{i}-O\right)\left(P_{i}-P\right)}{\left.\sqrt{\sum\left(O_{i}\right.}-\bar{O}\right)^{2}\left(P_{i}-\overline{P)^{2}}\right.}$

) رابطه (r)

$R M S E=\sqrt{\frac{\sum_{i=1}^{n}\left(P_{i}-O_{i}\right)^{2}}{n}}$

رابطه (r)

$M A E=\frac{\sum\left|O_{i}-P_{i}\right|}{n}$

) رابطه (i)

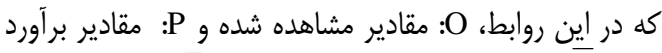

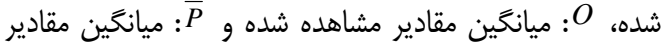

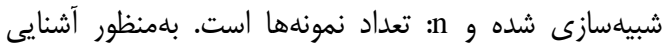
بيشتر با روش مدلسازى مورد استفاده در اين يثروهش،

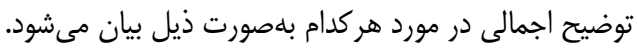

مدل منحنى سنجه رسوب 
ماشين بردار يشتيبان

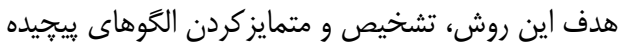

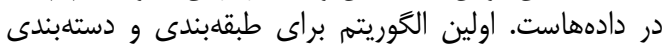

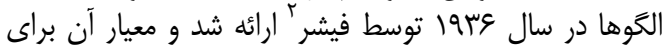

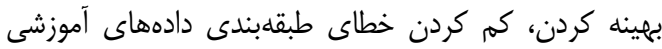

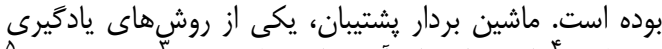

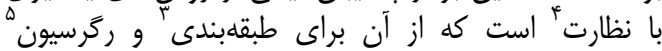

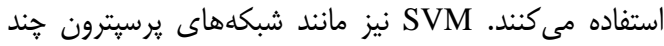

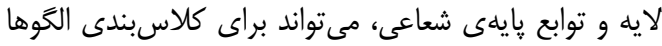

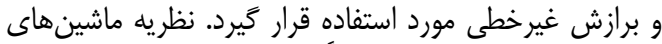

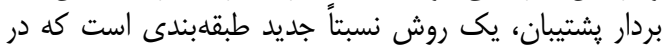

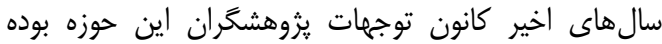

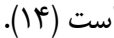

\section{نتايج و بحث}

نتايج مدلهاى منحنى سنجله، شبكه عصبى مصنوعى،

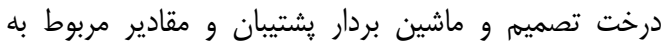

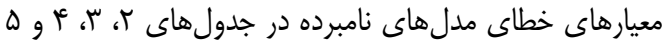

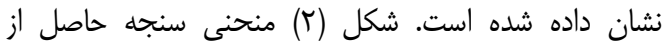
دادههاى آموزشى را نشان مى استهد.
ج) لايهى خروجى': آخرين لايه در مدل است كه نتايج مدل

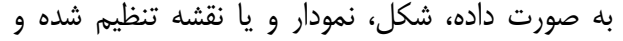

$$
\text { ارائه مىشود. }
$$

درخت تصميم كيرى

يادگيرى درخت تصميم كيرى، روشى برى براى تخمين توابع با

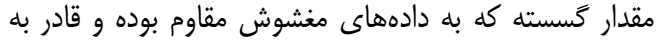

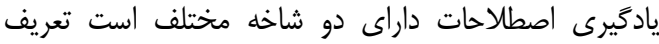

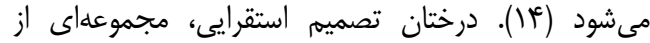

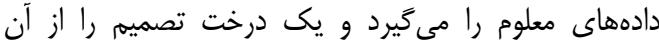

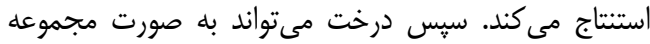

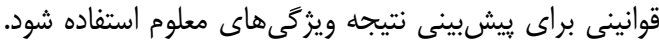

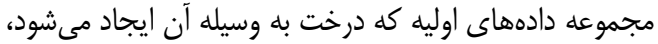

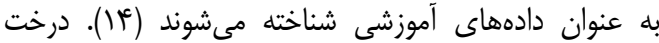

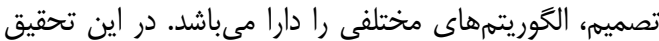

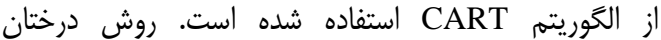
رَرسيونى و طبقهبندى (CART) اولين بار به وسيله برايمن

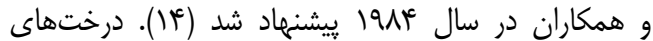

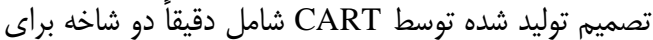

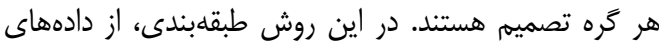

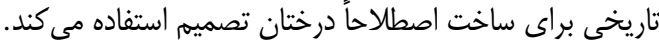

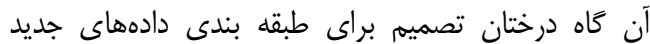

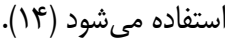

Table 2. Quantity of error criteria of sediment rating curve method

جدول r- مقادير معيارهاى خطا در روش منحنى سنجه رسوب

\begin{tabular}{|c|c|c|c|}
\hline RMSE (ton/day) & MAE (ton/day) & $\mathrm{R}$ & ورودى \\
\hline$\Delta \Delta \wedge \& Y / V V$ & $q \Psi \Delta Q / q \uparrow q$ & $\cdot / \Lambda$. & دير آت \\
\hline
\end{tabular}

جدول ب- نتايج معيارهاى آمارى خطا مربوط به مدل شبكه عصبى مصنوعى در تركيبات ورودى مختلف در مرحله آزمون Table 3.The results of statistical errors of artificial neural network model in different input combinations

\begin{tabular}{|c|c|c|c|}
\hline RMSE(ton/day) & MAE (ton/day) & $\mathrm{R}$ & ورودى \\
\hline$T / 4 \mathrm{~V}$ & TMET/AME & $\cdot / 19$ & دبى همان روز، بارش، تبخير، ميانكين دبى دو روز كذشته و مجموع بارش دو روز كذشته \\
\hline זr/T & $T V \cdot / 990$ &.$/ 91$ & دبى همان روز، بارش، تبخير، ميانكين دبى سه روز گذشته و مجموع بارش سه روز كذشته \\
\hline$r / / V$ & rag/vᄉr &.$/ 94$ & دبى همان روز، بارش، تبخير، ميانكَين دبى جهار روز كذشته و مجموع بارش حهار روز كذشته \\
\hline $1 / \% \Lambda$ & $1 . \Delta / A V 1$ &.$/ 91$ & U، تبخير، ميانكين دبى ينج روز كذشته و مجموع بارش ينج روز كذشته \\
\hline
\end{tabular}

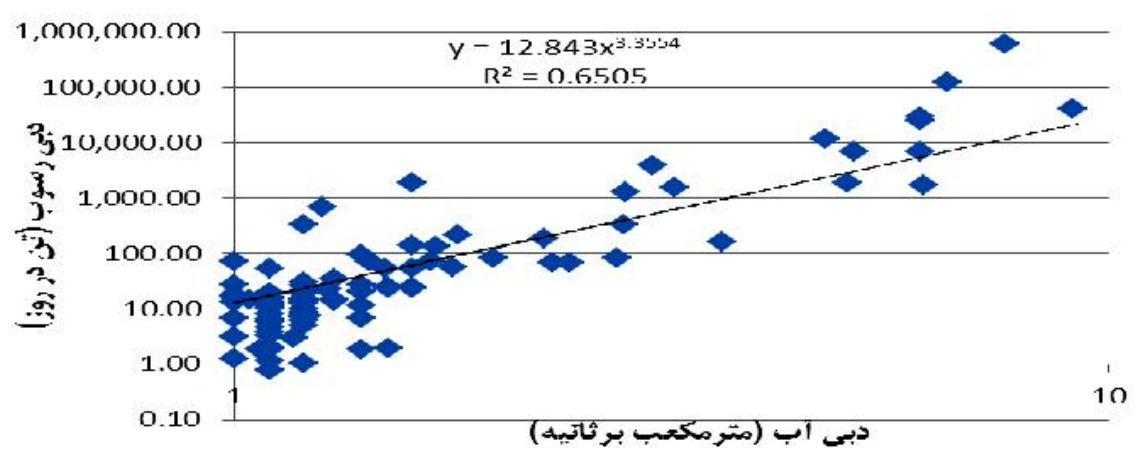

شكل r- منحنى سنجه حاصل از دادههاى آموزشى. (متردئ.

Figure 2- Rating Curve obtained from training data

\begin{tabular}{lll}
\hline 1- Output Layer & 2- Fisher & 3- Supervised Learning \\
4- Classification & 5- Regression
\end{tabular}


جدول عٔ- نتايج معيارهاى آمارى خطا مربوط به مدل درخت تصميم در تر كيبات ورودى مختلف در مرحله آزمون Table 4. The results of statistical errors of decision tree model in different input combinations in testing phase

\begin{tabular}{|c|c|c|c|}
\hline RMSE (ton/day) & MAE (ton/day) & $\mathrm{R}$ & ورودى \\
\hline Q..FF/VV & WGA/AII &.$/ 41$ & دبى همان روز، بارش، تبخير، ميانكين دبى دو روز كذشته و مجموع بارش دو روز كَذشته \\
\hline Q... $F q / \mu F$ & $V M \& \&|\Delta| f$ &.$/ 9 \mathrm{~V}$ & دبى همان روز، بارش، تبخير، ميانكين دبى سه روز كذشته و مجموع بارش سه روز كذشته \\
\hline 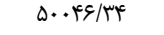 & $V A f \cdot / \cdot \Delta f$ &.$/ 99$ & 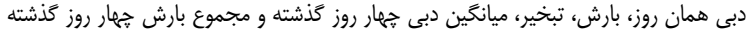 \\
\hline$Y M M I / \Delta S$ & DTEY &.$/ 99$ & دبى همان روز، بارش، تبخير، ميانكَين دبى ينج روز كذشته و مجموع بارش ينج روز كذشته \\
\hline
\end{tabular}

جدول ه- نتايج معيارهاى آمارى خطا مربوط به مدل ماشين بردار يشتيبان در تركيبات ورودى مختلف در مرحله آزمون

Table 5. The results of statistical errors of support vector machine model in different input combinations in testing phase

\begin{tabular}{|c|c|c|c|}
\hline RMSE (ton/day) & MAE (ton/day) & $\mathrm{R}$ & ورودى \\
\hline $4 / 1999$ & $1999 / 49 V$ &.$/ 994$ & دبى همان روز، بارش، تبخير، ميانگين دبى دو روز گذشته و مجموع بارش دو روز گذشته \\
\hline $1 / 18 \cdot 9$ & reV/arI &.$/ 999$ & دبى همان روز، بارش، تبخير، ميانكين دبى سه روز كذشته و مجموع بارش سه روز كذشته \\
\hline ./9498 & $|\Lambda T / K| S$ &.$/ 99$ & دبى همان روز، بارش، تبخير، ميانگين دبى جهار روز كذشته و مجموع بارش جهار روز كذشته \\
\hline.$/ 9991$ & 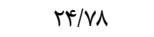 &.$/ 9999$ & دبى همان روز، بارش، تبخير، ميانگين دبى ينج روز كذشته و مجموع بارش ينج روز كذشته \\
\hline
\end{tabular}

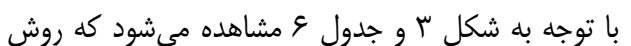

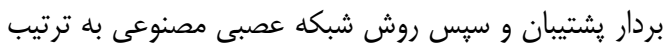

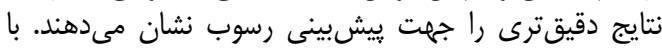

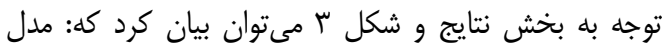

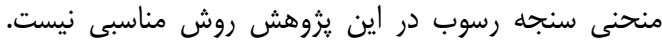

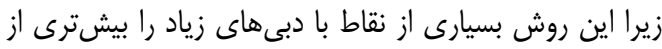

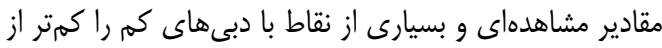

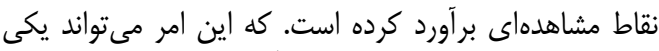
از ضعفهاى منحنى سنجه در برآورد رسوبات معلق ائ باشيد.

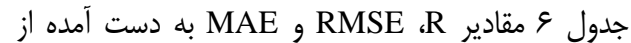
مدلهاى استفاده شده در تحقيق را انشان مى مدهد. مقايسه

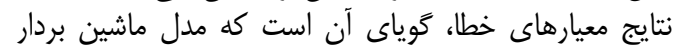

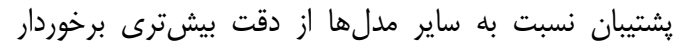

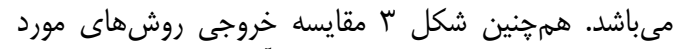

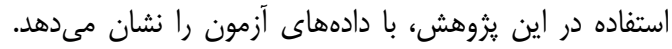

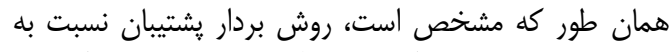

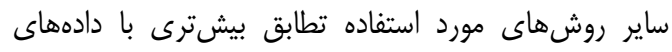

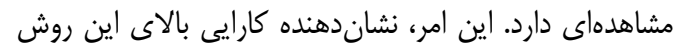
نسبت به ساير روشهاست.

جدول ع- نتايج مقايسه روشهاى نامبرده در بهترين حالت Table 6. Results of comparison for the mentioned methods for the best condition

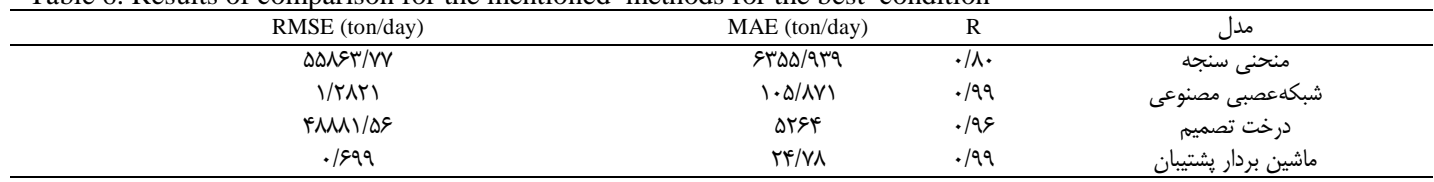

مصنوعى، رسوب معلق مربوط به دبىهاى بالا را باه خوبى إنى

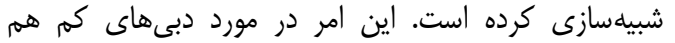

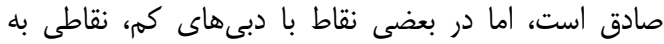
صورت استثناء نيز وجود دارند كه مناسب عمل نكرده ناس داست
در اين رابطه اكبرى و طالبى (1) نيز به اين نتيجه رسيدند

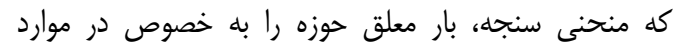

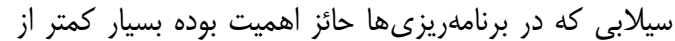

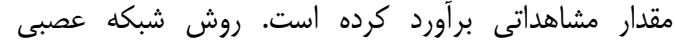

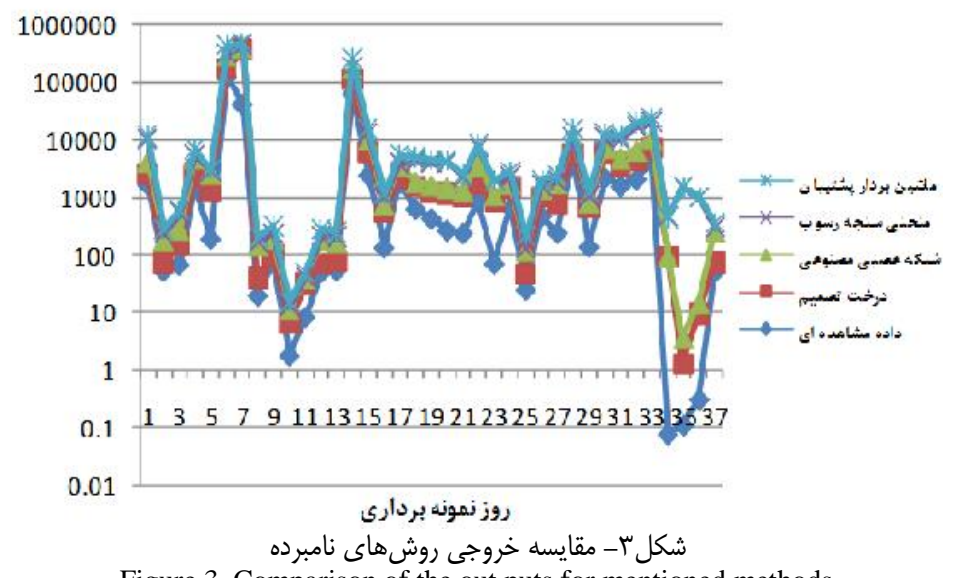

Figure 3. Comparison of the out puts for mentioned methods 


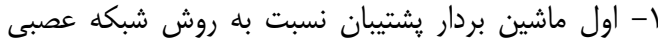

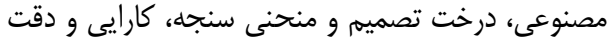

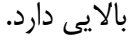

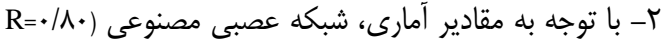

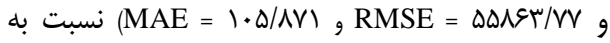

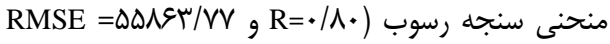

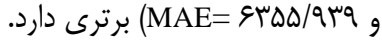

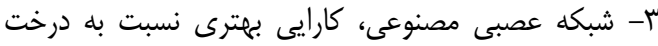

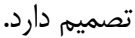

نتيجه به دست آمده از اين تحقيق نشان مىدهدي كه داردي

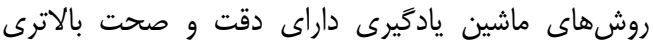

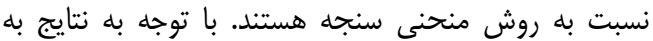

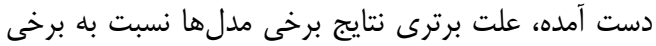

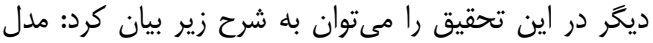

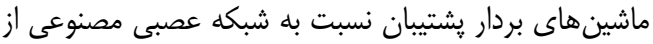

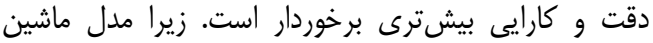

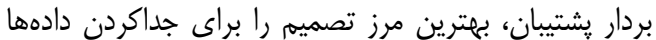

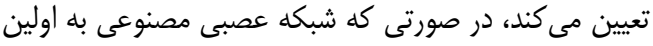

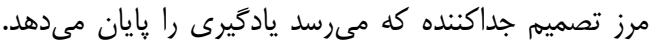

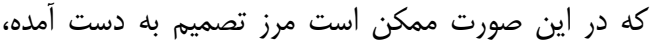

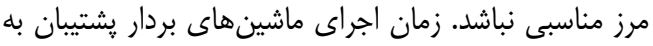

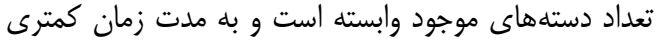

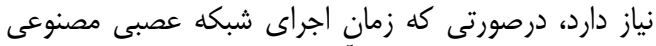

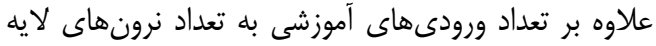

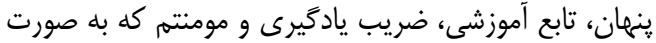
آزمون و خطا به دست مي آيند، وابسته است

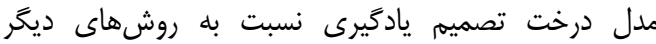

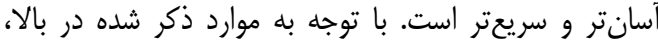

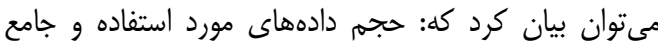

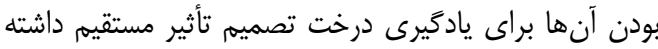

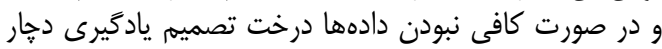

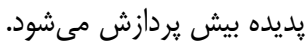

فلامكى و همكاران (ع)، در تحقيق خود نشان دادند كه

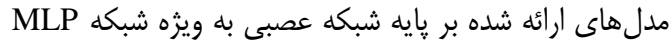

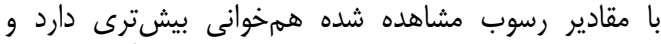

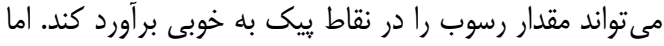

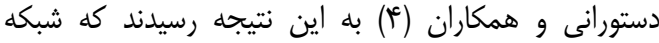

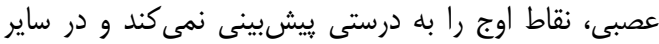

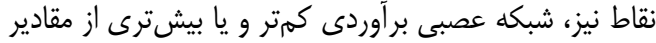

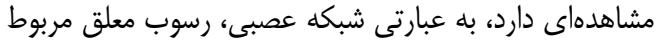

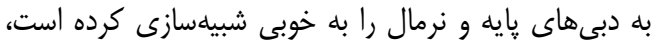

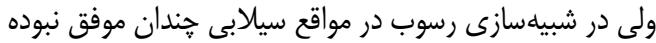

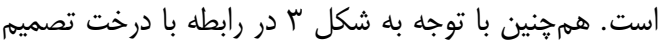

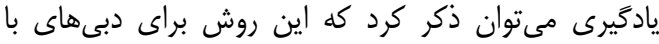

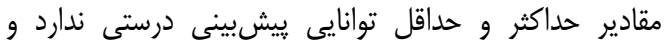

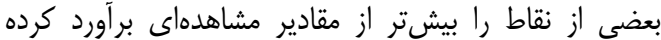

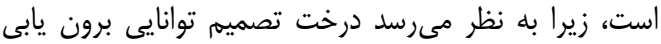

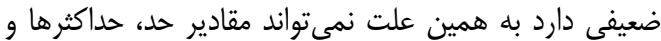

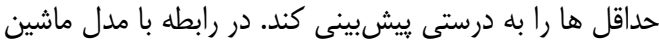

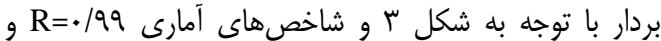
مA مئوان بيان كرد كه

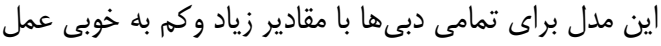

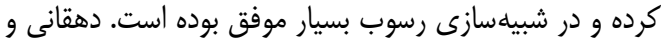

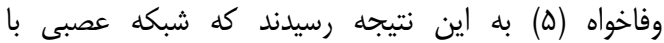

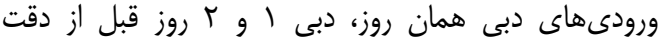

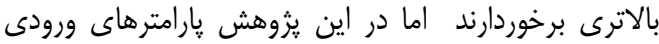

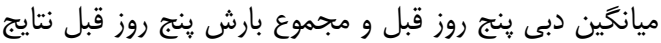

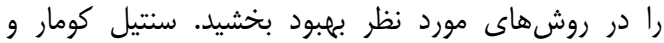

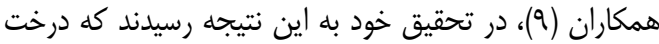

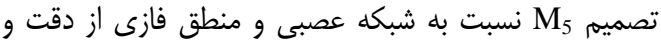

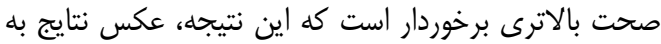

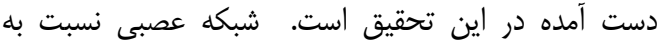
درخت تصميم در اين تحقيق ازصحت إن و درق دقت بالاترى

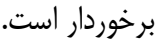
به طور كلى مى توان كفت كه: 
1. Akbari, Z. and A. Talebi. 2010. Estimation of Suspended Sediment Using Regression Decision Trees Method (Case Study Ilam Dam Basin Science and Technology of Agriculture and Natural Resources Journal, 17: 109-121 (In Persian).

2. Bhattacharya, B., R.K. Price and D.P. Solomatine. 2007. Machine Learning Approach to Modeling Sediment Transport. Journal of Hydraulic Engineering. 133: 440-450.

3. Bauer, P., S. Noatak and R.Winkler. 2007. Fuzzy Mathematical Methods for Soil Survey and Land Evaluation. Journal of Soil science, 40: 477-492.

4. Dastorani, M., Kh. Azimi Fashi, A. Talebi and M. Ekhtesasi. 2012. Suspended Sediment Estimation Using Artificial Neural Network (Case Study: Jamyshan watershed in Kermanshah). Journal of Watershed Management, 3: 61-74 (In Persian).

5. Dehghani, N. and M. Vafakhah. 2013. Comparison of Daily Suspended Sediment Load Estimations by Sediment Rating Curve and Neural Network Models (Case Study: Ghazaghli Station in Golestan Province). Journal of Water and Soil Conservation, 20: 221-230 (In Persian).

6. Falamaki, A., M. Eskandari, A. Baghlani and A. Ahmadi. 2013. Modeling Total Sediment Load in Rivers Using Artificial Neural Networks. Journal of Water and Soil Conservation, 2: 13-26 (In Persian).

7. Kakaei Lafdani, E., A. Pournemat, Roudsari, K. Qaderi and A. Moghaddam Nia. 2013. Predicting the Volume of Suspended Sediments using GMDH and SVM Models Based on Principal Component Analysis. 9th International River Engineering Conference Shahid Chamran University, Ahwaz, pp: 22-24 (In Persian).

8. Heng, S. and T. Suetsugi. 2013. Using Artificial Neural Network to Estimate Sediment Load in Ungauged Catchments of the Tonle Sap River Basin, Cambodia, Journal of Water Resource and Protection, 5: 111-123.

9. Senthil Kumar, A.R., C.S. Ojha, P. Manish Kumar Goyal, R.D. Singh and P.K. Swamee. 2012. Modeling of Suspended Sediment Concentration at Kasol in India Using ANN, Fuzzy Logic and Decision Tree Algorithms. American Society of Civil Engineers, 17: 394-404.

10. Shabani, M. and N. Shabani. 2012. Estimation of Daily Suspended Sediment Yield Using Artificial Neural Network and Sediment Rating Curve in Kharestan Watershed, Iran, Australian Journal of Basic and Applied Sciences, 6: 157-164 (In Persian).

11. Toloei, S., D. Hossenzadeh, M. Ghorbani, A. Fakhrefard and F. salmasi. 2011. Estimate Temporal and Spatial Suspended load river AJICHAI with Use from Geostatistics and Artificial neural Network. Issue Science Water and Soil, 21: 12-25 (In Persian).

12. Tabatabaei, M., K. Solaimani, M. Habibnejad Roshan and A. Kavian. 2014. Estimation of Daily Suspended Sediment Concentration Using Artificial Neural Networks and Data Clustering by Self Organizing Map (Case Study: Sierra Hydrometry Station- Karaj Dam Watershed). Journal of Watershed Management, 5: 98-116 (In Persian).

13. Yosefi, M. and R. Poorshariaty. 2014. Suspended Sediment Estimation Using Neural Network and Algorithms Assessment (Case Study: Lorestan Province), Watershed Management Journal, 5: 85-67. (In Persian).

14. Yosefi, M., A. Talebi and R. Poorshariaty. 2014. Application of Artificial Intelligence in Water and Soil Sciences. Yazd University publication, Yazd, Iran, 516 pp (In Persian).

15. Zhu, Y.M., X.X. Lu and Y. Zhou. 2007. Suspended Sediment Flux Modeling with Artificial Neural Network: An Example of the Longchunajianj River in the Upper Yangtze Catchment. Geomorphology, 84: 111-125. 


\title{
The Effectiveness of Intelligent Models in Estimating the River Suspended Sediments (Case Study: Babaaman Basin, Northern Khorasan)
}

\author{
Parisa Eshghi $^{1}$, Jalil Farzadmehr ${ }^{2}$, Mohammad Taghi Dastorani ${ }^{3}$ and Zeynab Arabasadi ${ }^{4}$ \\ 1- M.Sc. Student, Torbat-e Heydarie University \\ 2- Assistant Professor, Torbat-e Heydarie University, (Corresponding author: Farzadm102000@ gmail.com) \\ 3- Associate Professor, Ferdowsi University of Mashhad \\ 4- Instructor, University of Bojnord, Bojnord \\ Received: March 9, $2015 \quad$ Accepted: August 10, 2015
}

\begin{abstract}
Accurate estimation of the sediment volume carried by the rivers is important in water related projects and recognition and suggestion proper methods for estimating suspended sediment goals which should be conducted by related researches. Among the methods that have been recently used to model suspended sediment, machine learning based methods such as decision trees, support vector machine, and artificial neural networks are importance. In the present study, the applicability of such techniques in predicting suspended sediment load of Babaaman watershed in Bojnord, Iran has been evaluated. Input data for predicting Babaaman watershed' suspended sediments in this project are: Debi, suspended load, raining and evaporation, which are related to the statistical period 1349 to 1380 . In order to assess the accuracy and precision of the model results, statistical measures including R, RMSE, and MAE have been utilized. Consequently, the results of statistical value of R and RMSE for sediment rating curve method 0.80 and 55863.77, neural network 0.98 and 1.28, decision tree model 0.96 and 48881.56 and support vector machine 0.99 and 0.6998 . The obtained values reveal that the support vector machine was more consistent with the measured values compared to the abovementioned methods.
\end{abstract}

Keywords: Artificial Neural Network, Decision Tree, Sediment Rating Curve, Suspended Load, Support Vector Machine 